\title{
Cadaver study of the volume of the ovary in Bangladeshi women
}

\author{
Perven $\mathrm{HA}^{1}$, Nurunnabi $\mathrm{ASM}^{2}$, Ara $\mathrm{S}^{2}$, Jahan $\mathrm{MU}^{3}$ \\ ${ }^{I}$ Department of Anatomy, The Medical College for Women \& Hospital, Uttara, Dhaka, ${ }^{2}$ Department of \\ Anatomy, Dhaka Medical College, Dhaka, ${ }^{3}$ Department of Radiology \& Imaging, Bangabandhu \\ Sheikh Mujib Medical University (BSMMU), Dhaka.Email: shekhor19@yahoo.com
}

\begin{abstract}
Reproductive age, ovarian reserve and reproductive capability may be determined from the volume of the ovary. A cross-sectional, descriptive study was done in the Department of Anatomy, Dhaka Medical College, Dhaka, from January to December 2009, to see the variation in the volume of the ovary with age in Bangladeshi women. The study was performed on 140 post mortem human ovaries collected from 70 unclaimed female dead bodies which were in the morgue under examination in the Department of Forensic Medicine, Dhaka Medical College, Dhaka. The samples were divided into three age-groups including group A (10-13 years), group B (14-45 years) \& group C (46-52 years). Group A is pre-menarche group, group B represents reproductive age and group $\mathrm{C}$ is post menopausal group. The length, breadth and thickness of each ovary were measured by using a slide calipers. Then the volume of each ovary was determined by the product of its length, breadth and thickness multiplied by 0.524 , according to the Prolate ellipsoid formula. The mean volume of the right ovary was found higher than that of the left one in all age groups $(\mathrm{p}<0.001)$. The difference in mean volume of the ovary between group A \& group B, group B \& group C $(\mathrm{p}<0.001)$ and group A \& group C $(\mathrm{p}<0.01)$ were also statistically significant. The volume of the ovary increases with age and then gradually starts to decrease from menopause.
\end{abstract}

\section{Introduction}

The human ovary is a dynamic organ which continually changes in size and activity through life, as an integral part of the hormonal changes in female through before, during and after her reproductive life ${ }^{1}$. Reproductive age, ovarian reserve, reproductive capability and prediction of response to induced ovulation or superovulation all these phenomena in modern reproductive medicine may be determined from measurement of the volume of the ovary ${ }^{2,3}$. The accurate assessment of ovarian reserve will revolutionize the management of women requesting assisted conception or those who have had treatment for childhood cancer and those who are considering delaying a family for personal or professional reasons ${ }^{4}$. Ovarian morphology has become an important aspect of gynecological endocrinology, as volume is a crucial parameter to determine the extent of functional capability with hormonal integrity of the ovary ${ }^{5}$. Moreover, ovarian volume is an indicator of deviation from normal size and function to abnormal size and disease process like polycystic disease, tumour, ectopic pregnancy etc $^{6,7,8}$. For example, van Nagell et al. $(1995)^{8}$ performed transvaginal scan on 8500 women without any symptom and defined an ovary as abnormal if its volume was $>20 \mathrm{~cm}^{3}$ in premenopausal and $>10 \mathrm{~cm}^{3}$ in postmenopausal women. Thus, we usually depend on the western data which come from the subjects of different races and geographic conditions as well as different measuring procedures. Ovarian function related clinical conditions such as infertility, nonneoplastic follicular cyst and ovarian malignancy are common in our country ${ }^{9}$ and for perfect and complete evaluation of ovarian disease of Bangladeshi women, it is essential to establish an extensive data on the ovary of our own people ${ }^{10}$. Hence, the present study was aimed to see the variation in the volume of the ovary with age in Bangladeshi women and compare with that of western studies. It is expected that the findings of this study would help gynecologists, surgeons, sonologists and pathologists to adopt appropriate plan for diagnosis and treatment of the ovary.

\section{Materials and Methods}

Materials of the study: A cross-sectional, descriptive type of study was designed and done in the Department of Anatomy, Dhaka Medical College, Dhaka, from January to December 2009, based on collection of 140 human ovaries from 70 
unclaimed female dead bodies (age range 12-52 years) that were under examination in the Department of Forensic Medicine, Dhaka Medical College, Dhaka. All the samples were collected within 24-36 hours of death without any sign of putrefaction and taken from medicolegal cases excluding poisoning, any cutting or crushing injury to the ovary, ovary found in one side and diseased ovaries.

Methods: The ovary was taken and its outer surface was dried with blotting paper. After isolation, the samples were divided into three age-groups: group A (10-13 years), group B (14-45 years) \& group C (46-52 years), according to Kumar \& Malhotra $(2008)^{11}$. Here, group A is pre-menarche age group, group $\mathrm{B}$ represents reproductive age group and group $\mathrm{C}$ is post menopausal age group (Table-I).

Table-I: Grouping of the sample of the present study $(n=140)$

\begin{tabular}{lcll}
\hline Group & Age limit in years & Right & Left \\
\hline A & $10-13$ & 7 & 7 \\
B & $14-15$ & 50 & 50 \\
C & $46-52$ & 13 & 13 \\
\hline
\end{tabular}

At first, the length of the ovary was measured from its upper pole to the lower pole, then its breadth was measured at its maximum transverse diameter and the thickness was measured at the region of its maximum antero-posterior diameter, by using a slide calipers, according to Ahmed et al. $(2007)^{\mathbf{1 0}}$. Then the volume of each ovary was calculated which requires the measurement of the above three dimensions.

The Prolate ellipsoid formula is as follows: Volume $=$ Length $\times$ Breadth $\times$ Thickness $\times 0.524$ Statistical processing of data: All the data were recorded and processed; statistical analyses were done by using the SPSS 13.0 version. The comparison between right and left side was done by unpaired Student's ' $\mathrm{t}$ ' test and the comparison between different groups was done by One-way ANOVA.

\section{Results}

In the present study, the mean volume of the right ovary was found $2.66 \pm 0.23 \mathrm{~cm}^{3}$ in group A (10-13 years), $5.95 \pm 1.37 \mathrm{~cm}^{3}$ in group B (14-45 years) and $0.83 \pm 0.20 \mathrm{~cm}^{3}$ in group $\mathrm{C}(46-52$ years). The mean volume of the left ovary was found $1.78 \pm 0.20 \mathrm{~cm}^{3}$ in group A (10-13 years), $4.24 \pm 1.05 \mathrm{~cm}^{3}$ in group $\mathrm{B}$ (14-45 years) and $0.46 \pm 0.08 \mathrm{~cm}^{3}$ in group C (4652 years). The highest mean volume was found in group $\mathrm{B}$ and the lowest was in group $\mathrm{C}$ in both the ovaries. The mean volume of the right ovary was found higher than that of the left one in all age groups (Table-II). The difference in mean volume of the ovary between group A \& group B, group A
\& group C and group B \& group C were also statistically significant (Table-II).

Table-II: Volume of right and left ovary in different age group

\begin{tabular}{cccc}
\hline \multirow{2}{*}{ Age group } & \multicolumn{2}{c}{ Volume $\left(\mathrm{cm}^{3}\right)$} & \multirow{2}{*}{ P value } \\
\cline { 2 - 3 } & $\begin{array}{c}\text { Right } \\
(\text { mean } \pm \text { SD) }\end{array}$ & $\begin{array}{c}\text { Left } \\
(\text { mean } \pm \text { SD })\end{array}$ & \\
\hline A & $2.66 \pm 0.23$ & $1.78 \pm 0.20$ & $<0.001 * * *$ \\
$(\mathrm{n}=7)$ & $(2.35-2.99)$ & $(1.51-2.03)$ & \\
B & $5.95 \pm 1.37$ & $4.24 \pm 1.05$ & $<0.001 * * *$ \\
$(\mathrm{n}=50)$ & $(3.39-10.00)$ & $(2.11-7.42)$ & \\
$\mathrm{C}$ & $0.83 \pm 0.20$ & $0.46 \pm 0.08$ & $<0.001 * * *$ \\
$(\mathrm{n}=13)$ & $(0.54-1.09)$ & $(0.33-0.56)$ & \\
\hline & $\mathrm{P}$ value & $\mathrm{P}$ value & \\
A vs B & $<0.001 * * *$ & $<0.001 * * *$ & \\
A vs C & $<0.01 * *$ & $<0.01 * *$ & \\
B vs C & $<0.001 * * *$ & $<0.001 * * *$ & \\
\hline
\end{tabular}

Figures in parentheses indicate range. Comparison between right $\&$ left side done by unpaired Student's ' $t$ ' test and in between different age group were done by One-way ANOVA (PostHoc), ns = not significant, $* * * * * *=$ significant.

\section{Discussion}

Ivarsson, Nilsson \& Persson (1983) ${ }^{\mathbf{1 2}}$ studied on 34 girls by using pelvic ultrasound and found a mean ovarian volume ranging from $0.7 \mathrm{~cm}^{3}$ to $5.8 \mathrm{~cm}^{3}$. Higgins et al. (1989) ${ }^{7}$ found a sharp fall in ovarian volume at the menopause, with the average upper limit of normal falling from $18 \mathrm{~cm}^{3}$ in premenopausal women to $8 \mathrm{~cm}^{3}$ in postmenopausal women. Forabosco et al. (1991) ${ }^{\mathbf{1 3}}$ studied 5 left neonatal ovaries and found the mean volume $125.88 \mathrm{~mm}^{3}$. Thatcher \& Naftolin (1991) ${ }^{\mathbf{1 4}}$ stated that after menopause, the ovaries shrink to a size approximately one-half of that seen in the reproductive age. Pavlik et al. (2000) ${ }^{\mathbf{1 5}}$ examined 13963 women in ovarian cancer screening (aged between 25-91 years) by using transvaginal ultrasonogram and found mean ovarian volume 9.0 $\mathrm{ml}, 5.0 \mathrm{ml}, 4.9 \mathrm{ml}$ and $2.2 \mathrm{ml}$ in upto 36 years age group, 36-42 years age group, premenopausal age group and postmenopausal age group respectively. Kupesic et al. (2003) ${ }^{\mathbf{1 6}}$ found the mean ovarian volume $10 \mathrm{ml}, 8.30 \mathrm{ml}$ and $6.85 \mathrm{ml}$ in women <30 years, 31-35 years and 36-40 years respectively. Jonard, Robert \& Dewailly (2005) ${ }^{17}$ studied on 57 women with normal ovarian function by using transvaginal ultrasonogram and found a mean ovarian volume $>10 \mathrm{~cm}^{3}$. Healy (2008) ${ }^{18}$ stated that an average volume of ovary is $11 \mathrm{~cm}^{3}$ in reproductively mature woman. The findings of Ivarsson, Nilsson \& Persson ${ }^{12}$ and Thatcher \& Naftolin $^{14}$ are in agreement with the present study. In contrast, the findings of Higgins et al. ${ }^{7}$, Pavlik et al. $^{15}$, Kupesic et al. ${ }^{\mathbf{1 6}}$, Jonard, Robert \& Dewailly ${ }^{\mathbf{1 7}}$ and Healy ${ }^{18}$ are somewhat higher, and the findings of Forabosco et al. $^{\mathbf{1 3}}$ are lower than that of the present data. In most of the previous studies, the volume was recorded by using the ultrasound imaging, and that may naturally differ with the present study. However, in the present study, it was 
found that the volume of the ovary increases with age and then gradually starts to decrease from menopause. This may be a consequence of decrease in number of follicles, as because a highly significant correlation between primordial follicle population and ovarian volume is evident as reported in several previous studies ${ }^{2,7,14,16}$.

Conclusion: The volume of the ovary increases with age and then gradually starts to decrease from menopause. The results of the present study can be used as a standard reference for the ovaries of Bangladeshi women and to determine the abnormal evidences in Forensic and Pathologic corpses. However, further studies with larger sample and high technical backup are recommended.

Ethical clearance: This research work was approved by the Ethical Review Committee of Dhaka Medical College, Dhaka.

\section{Acknowledgement}

We would like to express our sincere gratitude to the authority of Health, Nutrition \& Population Sector Programme (HNPSP) of Directorate General of Health Services (DGHS) of the Government of the People's Republic of Bangladesh, and Dhaka Medical College, Dhaka, Bangladesh, for the research grant.

\section{References}

1. Lass A, Brinsden P. The role of ovarian volume in reproductive medicine. Hum Reprod Update 1999; 5(2): $256-66$

2. Wallace WH, Kelsey TW. Ovarian reserve and reproductive age may be determined from measurement of ovarian volume by transvaginal sonography. Hum Reprod 2004; 19(7): 1612-7.

3. Lass A, Skull J, McVeigh E, Margara R, Winston RML. Measurement of ovarian volume by transvaginal sonography before ovulation induction with human menopausal gonadotrophin for in-vitro fertilization can predict poor response. Hum Reprod 1997; 12(2): 294-7.

4. Charleston JS, Hansen KR, Thyer AC, Charleston LB, Gougeon A, Siebert JR, et al. Estimating human ovarian non-growing follicle number: the application of modern stereology techniques to an old problem. Hum Reprod 2007; 22(8): 2103-10.
5. Fox R, Hull M. Ultrasound diagnosis of polycystic ovaries. Ann NY Acad Sci 1993; 687: 217-23.

6. Erickson GF. Normal ovarian function. Clin Obstet Gynecol 1978; 21(1): 31-52.

7. Higgins RV, van Nagell JR Jr, Donaldson ES, Gallion $\mathrm{HH}$, Pavlik EJ, Endicott B, et al. Transvaginal sonography as a screening method for ovarian cancer. Gynecol Oncol 1989; 34(3): 402-6.

8. van Nagell JR Jr, Gallion HH, Pavlik EJ, Depriest PD. Ovarian cancer screening. Cancer 1995; 76(10 Suppl): 2086-91.

9. US Census Bureau. International Data Base, 2004.

10. Ahmed MS, Khalil M, Rahman MH, Mannan S, Sultana SZ, Ara ZG, et al. Morphological study of length, breadth and thickness of the ovary at different age group in Bangladeshi people. J Bangladesh Soc Physiol 2007; 2: 24-7.

11. Kumar P, Malhotra N. eds. Jeffcoate's principles of gynaecology. $7^{\text {th }}$ ed. New Delhi: Jaypee; 2008. p.36.

12. Ivarsson SA, Nilsson KO, Persson PH Ultrasonography of the pelvic organs in prepubertal and postpubertal girls. Arch Dis Child 1983; 58(5): $352-4$

13. Forabosco A, Sforza C, De Pol A, Vizzotto L, Marzona L, Ferrario VF. Morphometric study of the human neonatal ovary. Anat Rec 1991; 231(2): 201-8.

14. Thatcher SS, Naftolin F. The aging and aged ovary. Semin Reprod Endocrinol 1991; 9(3): 189-99.

15. Pavlik EJ, DePriest PD, Gallion HH, Ueland FR, Reedy MB, Kryscio RJ, et al. Ovarian volume related to age. Gynecol Oncol 2000; 77(3): 410-2.

16. Kupesic S, Kurjak A, Bjelos D, Vujisic S. Threedimensional ultrasonographic ovarian measurement and in vitro fertilization outcome are related to age. Fertil Steril 2003; 79(1): 190-7.

17. Jonard S, Robert Y, Dewailly D. Revisiting the ovarian volume as diagnostic criterion for polycystic ovaries. Hum Reprod 2005; 20(10): 2893-8.

18. Healy JC. Female reproductive system. In: Standring S, Borley NR, Collins P, Crossman AR, Gatzoulis MA, Healy JC, et al. eds. Gray's anatomy: the anatomical basis of clinical practice. $40^{\text {th }}$ ed. Edinburgh: Elsevier Churchill Livingstone; 2008. p.1293-9. 